\title{
Gender differences in students' learning achievements and awareness through residence energy saving game-based inquiry playing
}

\author{
Ugyen Dorji ${ }^{1}$ - Patcharin Panjaburee ${ }^{2}$. \\ Niwat Srisawasdi ${ }^{3}$
}

Received: 15 February 2015/Revised: 29 April 2015/Accepted: 2 May 2015/

Published online: 14 May 2015

(C) Beijing Normal University 2015

\begin{abstract}
Energy consumption and conservation is one of the important topics in Energy Education, whereby students are required to understand the factors of energy consumption leading to promote students' awareness on saving energy in residence. Moreover, inquiry-based learning strategy can be used to encourage students' learning in the topic. Although, several researchers studied on how to use digital games to improve understand the topic. However, a few studies have been conducted to investigate what the gender differences in playing and learning energy game-based learning are. In this vein, this paper address this issue by investigating the gender differences in learning achievement and energy-saving awareness through a digital game based on inquiry-based learning called Residence Energy Saving Battle (RES-battle). An experiment has been conducted on a secondary school physics course. The experimental results from 129 students indicate that the RES-battle can decrease the difference between female and male learning achievements reasonably and energy-saving awareness. This suggests a need to develop the game that can provide the opportunities for interaction on game screen and also with other students.
\end{abstract}

Keywords Game-based learning · Inquiry-based learning · Gender difference study $\cdot$ Energy education

Patcharin Panjaburee

panjaburee_p@hotmail.com

1 Gelephu Higher Secondary School, Gelephu Thromde, Sarpang, Bhutan

2 Institute for Innovative Learning, Mahidol University, 999, Phuttamonthon 4 Road, Salaya 73170, Nakorn Pathom, Thailand

3 Faculty of Education, Khon Kaen University, 123 Moo 16, Mittraphap Road, Muang, Khon Kaen 40002, Thailand 


\section{Introduction}

Learning about energy consumption and conservation in school science has become important in current research. Electricity is widely used for lighting or heating purposes and to make electrical equipment works. Due to the widespread use, most of the consumers are careless in its management. The amount of electrical energy usage occurs not only from residence's size but also from residents' behavior in using electrical equipment (Moll et al. 2005). In the past decade, several researchers attempted to provide the way to decrease the electricity usage in each residence. For example, Abrahamse et al. (2005) focused on altering the residents' behavior in the use of electrical equipment in an appropriate way. Maharaj-Sharma (2012) suggested that student energy learning is needed to apply and link with outside school and daily life.

Energy consumption and conservation is one of the important physics concepts in school science. Generally, this topic is a part of electricity learning unit in physics course. In the conventional physics class, student learned electricity as an attribute of electronics and consumption and conservation of energy in a form of employed energy calculation, but not as procedures as it is recognized in contemporary physics. As such, it is an instructional challenge to motivate student learning the concept meaningfully. Researchers have been using teaching approach to make the concept of electricity and energy consumption and conservation more meaningful for understanding to the students and for encouraging them to link the concept to daily life. For example, van den Berg and Grosheide (1993) mentioned that the conceptual ideas of electricity to the most important applications, i.e., electricity at home, and making a parallel connection and the aspect of electrical energy saving can advance the understanding of the mechanism of the electrical circuit by the students. Slotta and Chi (2006) recommended that the use of computerized instructional module, consisting of several running simulations which provide text explanation prompts, can facilitate conceptual development by first providing training in the concept's target ontology followed by normal instruction. It can help students gain a deeper understanding of electricity and electrical energy. To enhance physics conceptual learning of electric circuit for student, Schwedes and Dudeck (1996) used analogical inference from a model to the electric domain, and they found that student could reach a systematic view about electricity by analogical reasoning but the level of understanding electrical concepts was limited, as well as, Chiu et al. (2002) suggested that although using analogies or metacognition might help the learning process become more permanent, there is no significant conceptual development by these approaches. Another possibility for supporting students' meaningful learning in the domain of physics concept was seen in the use of inquiry-based learning with the use of interactive computer simulation as it is reported by Srisawasdi and Kroothkeaw (2014), and they mentioned that student could revise alternative conceptions and advance their own scientific conceptions through simulation-based open inquiry learning process. Thus, teaching students to use electric energy efficiently in their daily life to encourage them to construct conceptual understanding of energy consumption and conservation by themselves 
might be a useful way for saving energy in residence. In other words, digital interactive learning could be a useful way for conceptual learning of energy consumption and conservation and for simulating practices of saving energy in residence.

On the other hand, digital interactive learning is generally developed as multimedia learning units with simulations and games in many disciplines such as in mathematics, science, engineering, humanities, and social sciences (Cai et al. 2006; Eck 2006). Recent research attempted to purpose educational computer game which has advantage in students' habits and interests (Gee 2006; Prensky 2007) and indicated that the use of digital game is another useful method to improve energy consumption and conservation learning (Yang et al. 2012). Playing educational computer game requires prior knowledge or pre-existing learning experience that helps students apply the knowledge to make decision related to realistic situations (Papastergiou 2009) and can be considered as a learning tool for teaching the factual information as well as worksheet activities (Spraggins and Rowsey 1986). Therefore, developing a digital learning of energy consumption and conservation that integrates game-based learning technologies and inquiry-based strategy into learning of energy consumption and conservation may be a useful way to improve students' learning achievements on the topic and promote their energy-saving awareness in residence. However, the successful usage of the digital game depends on the features of digital game, the learning strategies, and human factors. Among the various human factors, gender difference plays an important role when playing digital game affecting learning performance (Paraskeva et al. 2010). The previous studies demonstrated that males outperformed females in the learning abilities within the digital game-based learning approach (Gee 2007; Unlusoy et al. 2010). However, in the same time, Yang and Chen (2010) revealed that the digital game with random puzzles for avoiding students memorize the answers could reduce the differences in the learning abilities between males and females. Obviously, the former inconsistent results indicated that gender differences are associated with learning performance within the digital game-based learning approach. In summary, gender differences and digital game-based learning are critical to learning performance. Moreover, the interaction between learning approaches (i.e., game-based learning and traditional teaching) and genders (i.e., female and male) for learning achievements and awareness has not been well addressed yet. Based on these concerns, this study aims to cope in this uninvestigated area.

The purpose of the empirical experiment is twofold (1) to empirically evaluate if there is interaction between learning approaches and gender differences for students' achievements, and (2) to empirically evaluate there is interaction between learning approaches and gender differences for students' energy-saving awareness in residence. For that reason, we used a digital game based on inquiry-based learning called Residence Energy Saving Battle (RES-battle) (Dorji et al. 2014), which targets secondary school students that attend class of physics course on energy consumption and conservation topic. 


\section{Related work}

\section{Teaching and learning energy consumption and conservation}

In the present world scenario, we are so much dependent on the electrical energy. This kind of energy is very important in the factories, business establishment, houses and in the recreational facilities. The shortage of electricity for few days or even few hours can cause lots of inconveniences. It even causes economic instabilities due to the reduction of industrial production. Many advanced and developed countries such as U.S.A and Europe have come up with numerous energy efficiency policies and programs which focus on the use of technologies that can save energy and design practices concentrating on the individual behavior (DeWaters and Powers 2011). But these could not help in terms of saving energy and cost-effectiveness, besides it could not reduce the daily household consumption of electrical energy in their every day's household usage (Vastamäki et al. 2005). These may be the reasons for most of the consumers being ignorant in their management of the electric power which add to the wastage of electric consumption in their day-to-day life (Boyde 2002). By only having highly sophisticated energy-saving appliances at home is not enough for the reduction of one's energy consumption, but developing advocacy is more important for saving electrical energy and developing awareness to manage the daily consumption of electricity. In order to fulfill this goal, energy education has become a very important element to educate students on the basic energy concept on daily electrical energy consumption and conservation. It help students identify basic factors on which energy consumption depend and provide useful ways for reducing daily energy consumption both in and outside of their home and school (Haakana et al. 1997). Understanding the learners and integrating appropriate learning approaches for teaching the concept is very important for any effective learning process. Thus, introducing the concept of energy education into the ways the students understand is crucial for any educator (Gustafson and Branch 2002).

In the recent years, the education system supplied hundreds of computers all over the nation under the project "Chiphen Rigphel Project" (Information Communication Technology-ICT Project) with grant from government of India. The objective of the project is to equip every student with IT literacy and improve science education. Now the system is stressing more on the practical-oriented learning that enables students to acquire the skills that can be applied in the practical context. So, the system has observed digital learning as one of the ways to achieve that goal. Therefore, there is a strong need for teachers to change the instructional practices from teacher-centeredness to child-centeredness by practicing effective teaching strategies with the integration of digital learning like computer games, animations, simulations, and more particularly in learning abstract concepts in science curriculum, especially on topic energy consumption and conservation. 


\section{Educational computer game and gender differences}

In addition to learning achievements and awareness on energy consumption and conservation, the educational game might be used to support students' learning on the topic. As shown in several studies, Sofoluwe (2007) suggested that the educational game can serve as a tool of learning for encouraging and motivating students learning within enjoyable environment. In the recent years, several researchers developed the educational game to support students' academic achievement, including mathematics (Lee and Chen 2009), language (Chen et al. 2011), software programming (Connolly et al. 2007), management education (Chen et al. 2013; Kiili 2007), medical education (Moreno-Ger et al. 2008), and sports education (Mueller et al. 2010).

Some studies used the educational game to promote attitude and awareness. For example, a study by Evans et al. (2007) demonstrated that while learning through games, students developed positive attitudes regarding the environment besides they also behave in an environmentally responsible manner. Computer simulation games can be implemented in various teaching learning fields for promoting environmental awareness and exploring attitudes toward environmental conservation (Torres and Macedo 2000). Moreover, a recent study by Yang et al. (2012) has shown that a digital game-based learning system can be used as a strategy to promote the selfawareness regarding energy conservation and enable learning energy conservation with higher motivation and willingness. The developed unit incorporated gamebased learning environment for nurturing a cyberpet where learners cautiously operate electric appliances to ensure a balance between the comfort and survival of the pet and the reduction of the energy consumption. The results advocated that the system had positively affected learners' self-awareness, learning motivation, and willingness to conserve energy.

In the past decade, several researchers studied the interaction between educational computer game and gender differences. For example, Agosto (2004) found that both females and males at the preschool age showed the same enthusiasm in computer games. Vogel et al. (2006), through the meta-analysis of various studies on gender, showed that there is no significant performance difference between the two genders and concluded that both genders benefited from games cognitively. Moreover, Papastergiou (2009) found that there were no gender differences in terms of science achievement of high school students when using computer game. They also showed better performance than those who did not use computer game. In contrast, Gee (2007) and Unlusoy et al. (2010) revealed that males show more interest in digital games than females. Therefore, among various human factors, gender difference plays an important role when playing digital game affecting learning performance (Paraskeva et al. 2010).

Consequently, it is a challenge to study the interaction between learning approaches (i.e., game-based learning and traditional teaching) and genders (i.e., female and male) for learning achievements and awareness on energy consumption and conservation topic in this study. 


\section{The energy consumption and conservation game-based learning}

For the purpose of study, we used an energy consumption and conservation game which was developed based on inquiry-based learning strategy named RES-battle (Dorji et al. 2014). Figure 1 shows the structure of the game, which is composed of five interfaces for linking between students and the game system (i.e., an orientation interface, an engaging saving energy interface, an exploring energy consumption factors interface: main gaming interface, an explaining concept interface, and an elaborating knowledge interface). Furthermore, there are four databases to store important information during playing the game, including an item bank database, an electrical appliance database, a hint database, and a student portfolio database.

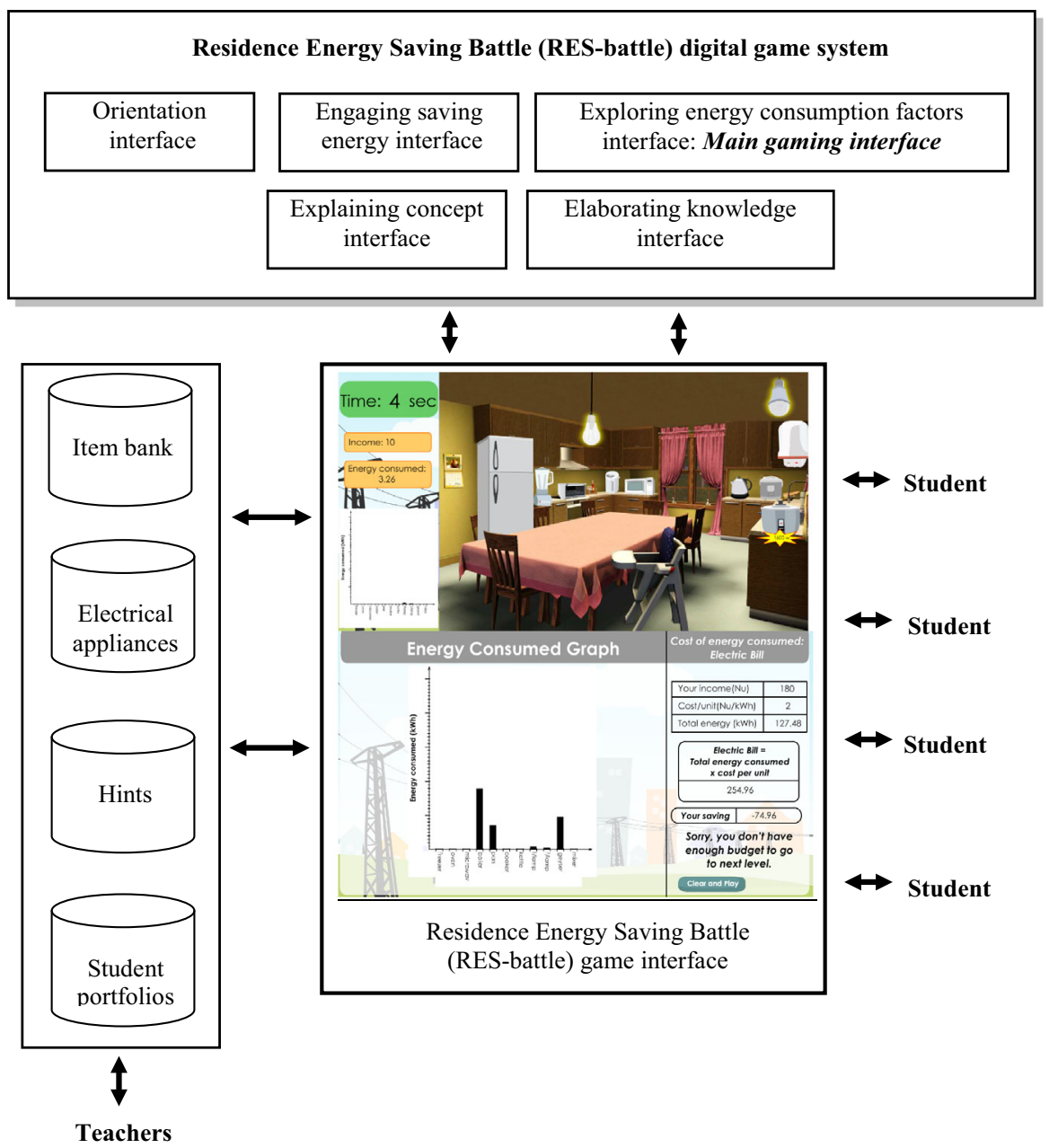

Fig. 1 The structure of the Residence Energy Saving Battle (RES-battle) game 
The exploring energy consumption factors interface, which is the main gaming interface, is designed in line with practical situations of energy consumption in our daily life. To save money and minimize energy consumption, these help the students in developing sense of awareness on energy conservation. The objectives of the RES-battle are introduced to the students, such as the students should be able to know how energy consumption is calculated in terms of money and also how can they apply those factors in monitoring power bill by playing the RES-battle. The rules and basic functions of the RES-battle are demonstrated to the students, such as the RES-battle is designed with scenarios of home comprising electrical appliances that are commonly operated. It is divided into two different difficulty levels in which the students can go to the second level by passing the first level. Each level has 30-second playing time. To get into another level, the students should have enough income/budget earned from the current stage. In doing so, the students should hunt/collect hidden coins which depend upon wattage of those appliances in that room. The students have to take cautious decisions on selecting/clicking on appliances to get those coins because every time they collect coins, it activates the appliance which consumes energy, and they have to pay at the end. While playing the RES-battle, whatever coins are accumulated and how much energy has consumed are automatically calculated and displayed in graphical format at the side of the game screen as shown in Fig. 2. These help students apply their theoretical knowledge, skills, and strategies to make decisions in their assigned role which promotes the understanding of the concept. The wattage of each appliance will be shown randomly at certain interval. The value of hidden coins in each appliance remains constant whether it is chosen at the beginning or at last. In this step, the students are encouraged to inquire factors of energy consumption which are wattage of the appliance and duration of usage.

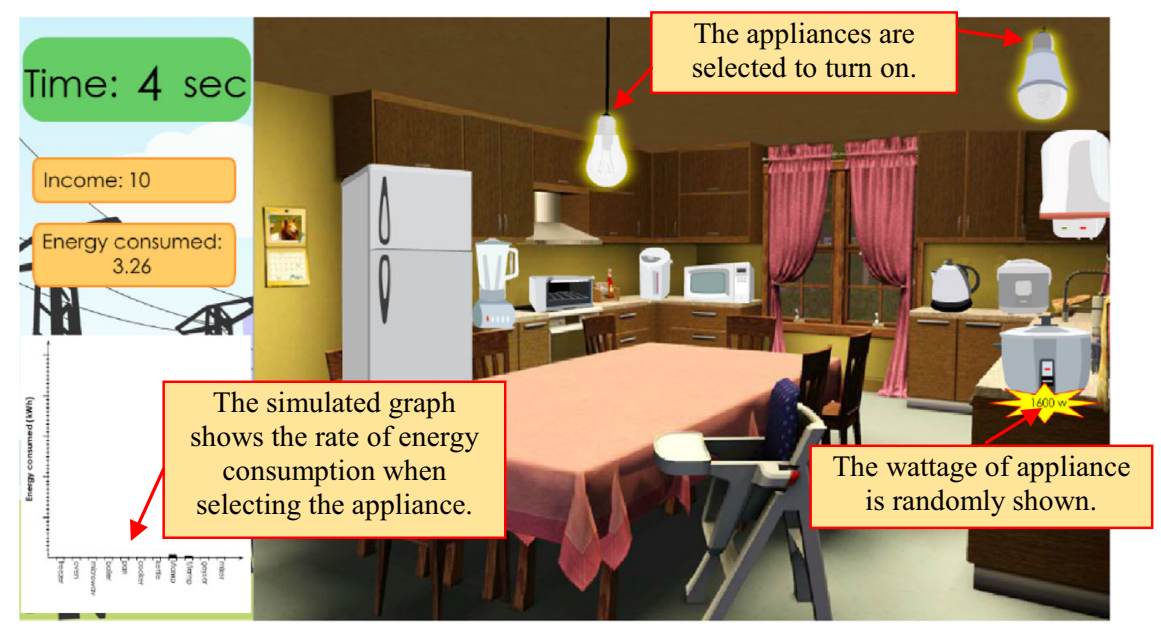

Fig. 2 Illustrate playing the Residence Energy Saving Battle (RES-battle) in the first level 
At the end of $30 \mathrm{~s}$, the RES-battle automatically is stopped and displays "Time Up", after that the simulated graph for energy consumption will be displayed for those appliances that the students operated during the game as shown in Fig. 3. Based on that, the cost for energy consumed is calculated and then saving of the students is shown (your saving = income - cost of energy). If the saving is positive, the player can continue the game in the second level with more difficulty, otherwise they cannot go further or can play again.

\section{Research design}

To investigate the interaction between learning approaches (i.e., game-based learning and traditional teaching) and genders (i.e., female and male) for learning achievements and awareness in this study, a conceptual pre-test and conceptual post-test, and a pre-awareness questionnaire and post-awareness questionnaire designed experiment with non-equivalent groups were used. The aim of the experiment was to compare the learning achievements and energy-saving awareness of the students who learned with the RES-battle and those who learned with the traditional teaching and learning approach.

\section{Participants}

An experiment was conducted on a secondary school energy consumption and conservation topic. A total of 129 tenth graders in eastern Bhutan participated in this study. The mean age of the participants is sixteen. Two classes were assigned to be the experimental group, and the others were the control group. The experimental group included 69 students (31 males and 38 females), while

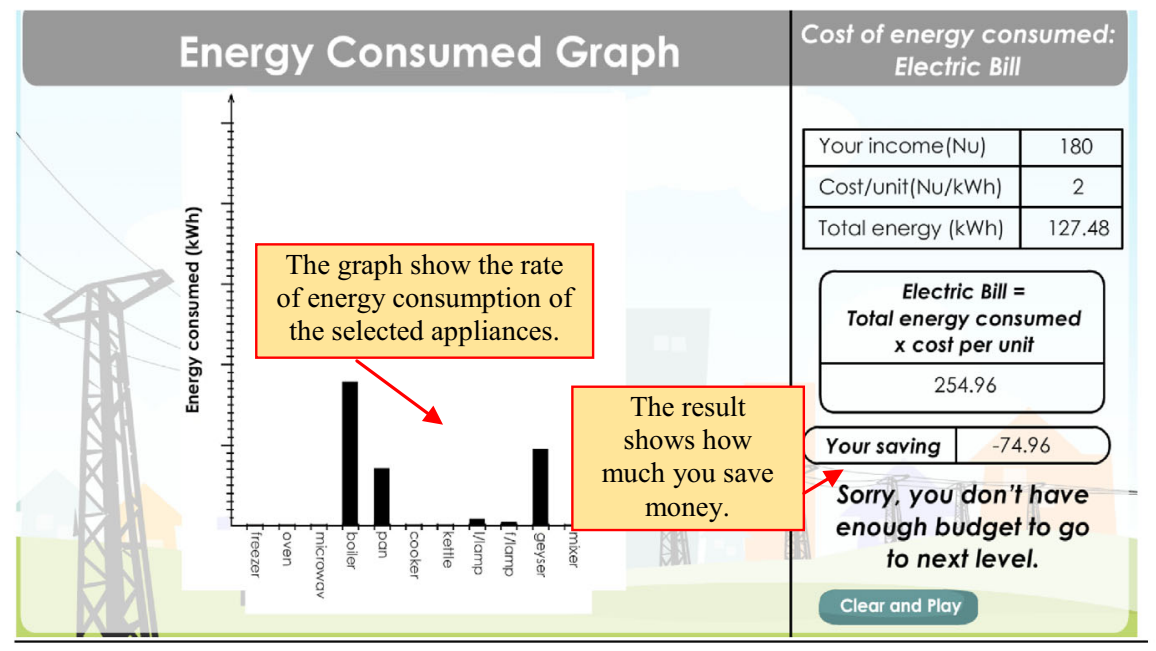

Fig. 3 Illustrate results of playing the Residence Energy Saving Battle (RES-battle) in the first level 
the control group had 60 students (32 males and 28 females). In this study, the same teacher taught the students in the four classes in order to avoid the influence of different experienced teachers on the experimental results. The students in the control group learned with the lesson in traditional teaching approach by text book with inquiry-based learning method, while those in the experimental group learned with the RES-battle.

\section{Research tools}

The research tools in this study were the conceptual pre-test and conceptual posttest for measuring students' learning achievement of the learning activity, and the pre-awareness questionnaire and post-awareness questionnaire for measuring students' energy-saving awareness in residence after finishing learning activity.

The conceptual pre-test aimed to evaluate whether the basic knowledge of the energy consumption of the two groups was equivalent before they participated in the learning activity. It consisted of 20 multiple-choice items and one point was scored for each correct answer, giving a perfect score of 20 . The conceptual post-test aimed to measure the students' knowledge of main factors of electrical energy consumption in electrical appliances, calculating the energy consumption and cost of operating daily used household electrical appliances. It consisted of 20 multiplechoice items and one point was scored for each correct answer, giving a perfect score of 20 . Both the pre-test and the posttest were designed and examined by three experienced teachers teaching physics courses.

The pre- and post-awareness questionnaire were adapted from Kang et al. (2012). Each questionnaire consisted of fifty items on a 3-point Likert scale in which "3" represents "know very well," "2" represents "know some of them," and " 1 " represents "don't know at all." The Cronbach's alpha value for the awareness questionnaire was 0.99 , indicating good reliability in internal consistency.

\section{Experimental process}

In this study, the experiment was conducted on the energy consumption and conservation unit in a secondary school physics course. Before the experiment, both groups of students were taught by the same teacher about the basic concept of the energy consumption and conservation unit $(30 \mathrm{~min})$. Following that, the students took the conceptual pre-test $(30 \mathrm{~min})$ and the investigation of pre-awareness questionnaire regarding saving energy in residence (15 min).

The learning activities were conducted for a period of $90 \mathrm{~min}$. The learning content for both the experimental and control groups was the same. The students in the experimental group learned with the RES-battle, whereas those in the control group were taught with conventional teaching method. After learning activity, all students took the conceptual post-test $(30 \mathrm{~min})$ and the investigation of postawareness questionnaire regarding saving energy in residence (15 $\mathrm{min})$. 


\section{Results}

\section{Students' learning achievements}

Among various human factors, gender difference plays an important role when playing digital game affecting learning performance (Paraskeva et al. 2010). Nevertheless, the interaction between learning approaches (i.e., game-based learning and traditional teaching) and genders (i.e., female and male) on learning achievements and awareness has not been well addressed yet. Accordingly, this study investigated the impact of the RES-battle approach on the learning achievements of the students with gender differences (i.e., female and male). A two-way ANCOVA was employed using the conceptual pre-test scores of learning achievement as a covariate, learning approach (RES-battle game and traditional teaching and learning) and gender (female and male) as independent variables, while the conceptual post-test scores of learning achievement were a dependent variable.

Before conducting the ANCOVA test, the assumption of homogeneity of regression was tested. We found that the homogeneity of regression was not violated with $F=0.575(p>0.05)$. Therefore, two-way ANCOVA test can be used to analyze the conceptual post-test scores of the four groups. As shown in Table 1, it is found that the interaction between dependent variables was not significant $\left(F=0.136, p>0.05, \eta^{2}=0.066\right)$ on the students' learning achievements. In Table 1, we notice that a significant effect was the learning approaches $\left(F=23.695, p<0.05, \eta^{2}=0.998\right)$ on students' learning achievements, implying that the dependent variables affect the learning achievements in different ways. It implies that a simple main-effect analysis was required to examine the effects of the learning approaches on the learning achievements of the gender differences.

Table 2 shows the descriptive data on the adjusted conceptual post-test scores of learning achievement of all the four groups. Moreover, Table 3 shows the results of the simple main-effect analysis. It is found that the female students who learned with different learning approaches revealed significantly different learning achievements $\left(F=10.452, p<0.05, \eta^{2}=0.998\right)$, that is, the RES-battle game approach had significantly better positive effects on female students' learning achievements $($ Mean $=12.95$, SD. $=2.94)$ than the traditional teaching approach had $($ Mean $=10.32$, SD. = 3.56). In addition, it is found that the male students who learned with different leaning approaches revealed significantly different learning

Table 1 Results of two-way ANCOVA on students' learning achievements

\begin{tabular}{lrrrrr}
\hline Source & \multicolumn{1}{c}{ SS } & \multicolumn{1}{c}{$d f$} & \multicolumn{1}{c}{ MS } & \multicolumn{1}{c}{$F$} & \multicolumn{1}{c}{$\eta^{2}$} \\
\hline Learning approaches & 251.296 & 1 & 251.296 & $23.695^{*}$ & 0.998 \\
Genders & 8.387 & 1 & 8.387 & 0.791 & 0.143 \\
Learning approaches $\times$ genders & 1.446 & 1 & 1.446 & 0.136 & 0.066 \\
Error & 1315.068 & 124 & 10.605 & & \\
\hline
\end{tabular}

$* p<0.05$ 
Table 2 The descriptive data of the learning achievements of the students who learned with different learning approaches

\begin{tabular}{lllll}
\hline Genders & Learning approaches & Adjusted mean & SE & $N$ \\
\hline Female & RES-battle game & 12.970 & 0.529 & 38 \\
& Traditional learning & 10.373 & 0.620 & 28 \\
\multirow{2}{*}{ Male } & RES-battle game & 13.705 & 0.587 & 31 \\
& Traditional learning & 10.682 & 0.578 & 32 \\
\hline
\end{tabular}

Table 3 The simple maineffect analysis of students' learning achievements

\begin{tabular}{llllll}
\hline Dependent variables & SS & $d f$ & MS & $F$ & $\eta^{2}$ \\
\hline Learning approaches & & & & & \\
$\quad$ Female & 109.767 & 1 & 109.767 & $10.452^{*}$ & 0.889 \\
$\quad$ Male & 143.929 & 1 & 143.929 & $13.269 *$ & 0.948 \\
Genders & & & & & \\
RES-battle game & 7.691 & 1 & 7.691 & 0.842 & 0.148 \\
$\quad$ Traditional learning & 2.415 & 1 & 2.415 & 0.195 & 0.072 \\
\hline
\end{tabular}

- - RES-Battle game approach

$\longrightarrow$ Traditional teaching approach

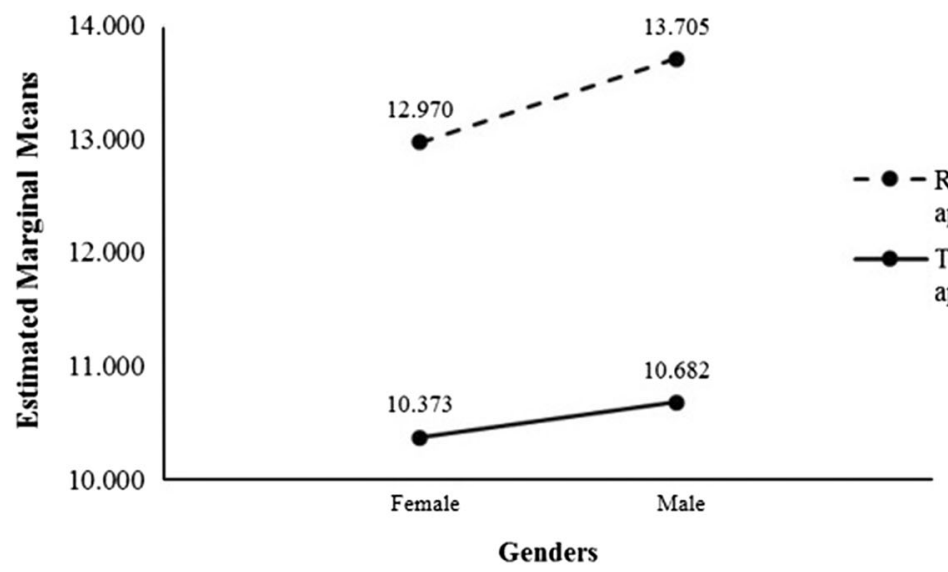

Fig. 4 Interaction between learning approaches and genders for learning achievements

achievements $\left(F=13.269, p<0.05, \eta^{2}=0.948\right)$, that is, the RES-battle game approach had significantly better positive effects on male students' learning achievements $($ Mean $=13.74, \mathrm{SD} .=3.13)$ than the traditional teaching approach had $($ Mean $=10.72$, SD. $=3.43)$.

On the other hand, with regard to the impact of different learning approaches on the learning achievements of female and male students, no significant differences were found between those who learned with the RES-battle game approach and those who learned with the traditional teaching approach. This implies that both the female and male students gained the same level of knowledge while learning with the RES-battle game approach. In addition, when learning with the traditional 
teaching approach, the female students gained the same level of knowledge as that of male students.

Figure 4 shows the interaction between learning approaches and genders for the students' learning achievements. It represents that students who participated in the RES-battle game-based learning activities had better learning achievements than those who learned with the traditional teaching and learning activities. It clearly demonstrates that the RES-battle game-based learning approach benefited the female students and male students more than the traditional teaching approach did. Moreover, when learning with the RES-battle game-based learning approach, female and male students benefited similarly. In addition, when learning with the traditional teaching approach, female and male students benefited similarly.

\section{Students' awareness on saving energy in residence}

To examine how students' genders (i.e., female and male) for a game are connected with students' awareness on saving energy in residence after learning in the different learning approaches, a two-way ANCOVA was employed. The prequestionnaire ratings of awareness were a covariate; learning approach (RES-battle game and traditional teaching and learning) and gender (female and male) were independent variables, while the post-questionnaire ratings of awareness were a dependent variable.

Before conducting the ANCOVA test, the assumption of homogeneity of regression was tested. We found that the homogeneity of regression was not violated with $F=1.346(p>0.05)$. Therefore, a two-way ANCOVA test can be used to analyze the post-questionnaire ratings of awareness of the four groups. As shown in Table 4, it is found that the interaction between dependent variables was not significant $\left(F=1.293, p>0.05, \eta^{2}=0.204\right)$ on the students' awareness. In Table 4 , we notice that a significant effect was the learning approaches $(F=5.809$, $p<0.05, \eta^{2}=0.667$ ) on students' awareness, implying that the dependent variables affect the awareness in different ways. It implies that a simple maineffect analysis was required to investigate the effects of the learning approaches on the awareness of the gender differences.

Table 5 shows the descriptive data on the adjusted post-questionnaire ratings of awareness of all four groups. Moreover, Table 6 shows the results of the simple maineffect analysis. It is found that the female students who learned with different leaning approaches revealed significantly different awareness $(F=9.174, p<0.05$,

Table 4 Results of the two-way ANCOVA on students' awareness on saving energy in residence

\begin{tabular}{lrrrrr}
\hline Source & SS & $d f$ & MS & $F$ & $\eta^{2}$ \\
\hline Learning approaches & 0.498 & 1 & 0.498 & $5.809^{*}$ & 0.667 \\
Genders & 0.284 & 1 & 0.284 & 3.311 & 0.439 \\
Learning approaches $\times$ genders & 0.111 & 1 & 0.111 & 1.293 & 0.204 \\
Error & 10.640 & 124 & 0.086 & & \\
\hline
\end{tabular}

$* p<0.05$ 
$\left.\eta^{2}=0.847\right)$, that is, the RES-battle game approach had significantly better positive effects on female students' awareness (Mean $=2.57$, SD. $=0.23$ ) on saving energy in residence than the traditional teaching approach had (Mean $=2.42$, SD. $=0.34$ ), while no significant difference was found between the awareness of male students who learned with the two different approaches. In addition, it is found that the male students who learned with the traditional teaching approach revealed significantly better awareness than female students $\left(F=4.279, p<0.05, \eta^{2}=0.529\right)$, that is, the traditional teaching approach had significantly better positive effects on male students' awareness (Mean $=2.54$, SD. $=0.34$ ) than female students (Mean $=2.42$, SD. $=0.34$ ), while no significant difference was found between female and male students who learned with the RES-battle game approach.

On the other hand, with regard to the impact of different learning approaches on the awareness on saving energy in residence of female and male students, no significance was found between those who learned with the RES-battle game approach, while there was significant difference on those who learned with the traditional teaching approach. This implies that awareness on saving energy in residence was promoted among the female and male students while learning with the RES-battle game approach in a similar manner. In addition, when learning with the traditional teaching approach, the male students were found to have better awareness on saving energy in residence than the female students.

Figure 5 shows the interaction between learning approaches and genders for the students' awareness. It demonstrates that students who participated in the RESbattle game-based learning activities had better awareness than those who learned with the traditional teaching and learning activities. It clearly demonstrates that the RES-battle game-based learning approach benefited the female students and male students more than the traditional teaching approach did. Moreover, when learning with the RES-battle game-based learning approach, awareness was promoted among the female and male students in a similar manner. In addition, when learning with the traditional teaching approach, the male students were found to have better awareness on saving energy in residence than the female students.

\section{Discussion and conclusions}

This study evaluated the performance of a digital game based on inquiry-based learning called RES-battle (Dorji et al. 2014) targeted at secondary school students' learning of physics course on energy consumption and conservation topic. This study indicates that the RES-battle game-based learning approach successfully

Table 5 The descriptive data of the awareness of the students who learned with different learning approaches

\begin{tabular}{lllll}
\hline Genders & Learning approaches & Adjusted mean & SE & $N$ \\
\hline Female & RES-battle game & 2.587 & 0.048 & 38 \\
& Traditional learning & 2.400 & 0.057 & 28 \\
Male & RES-battle game & 2.620 & 0.053 & 31 \\
& Traditional learning & 2.555 & 0.052 & 32 \\
\hline
\end{tabular}


Table 6 The simple maineffect analysis of students' awareness on saving energy in residence

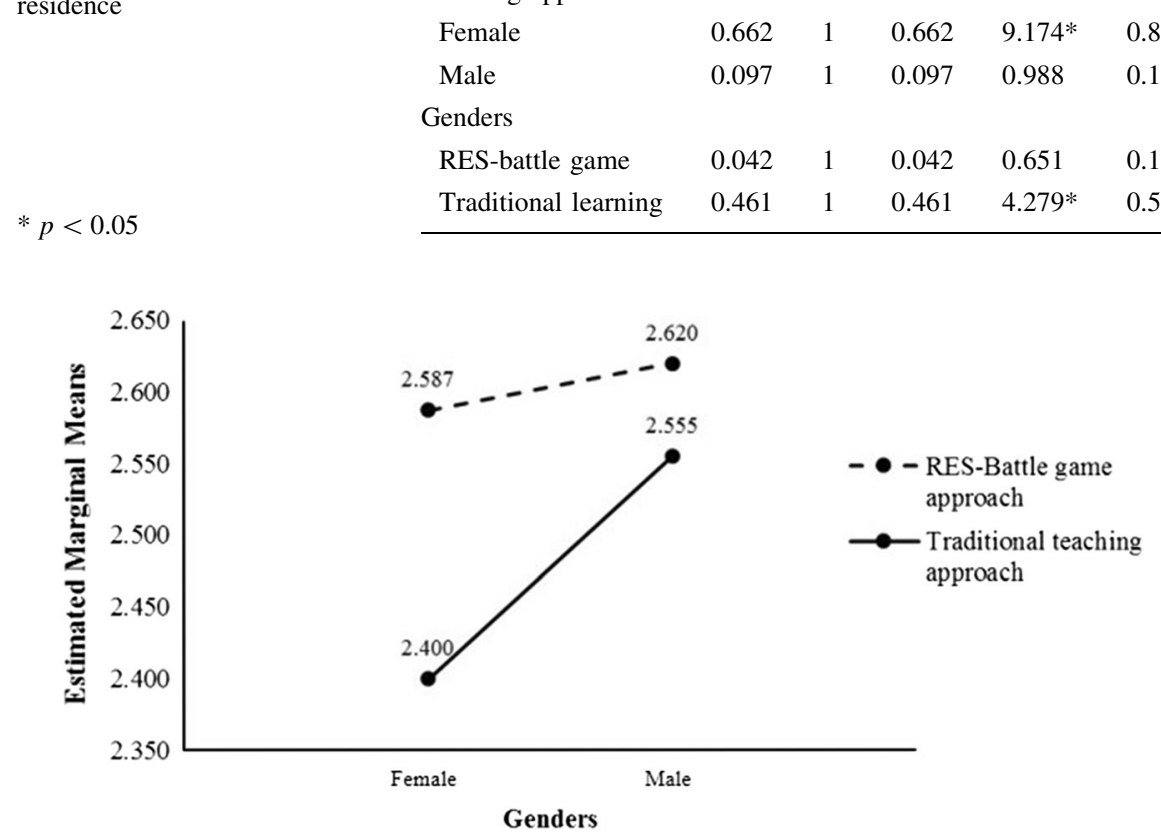

Fig. 5 Interaction between learning approaches and genders for awareness on saving energy in residence

supported students' learning achievement on energy consumption and conservation topic and their awareness on saving energy in residence when compared to the traditional teaching approach. The main objective of the presented study is to examine the interactions between students' genders and learning achievements, and between students' genders and awareness on saving energy in residence regarding the RES-battle game and the traditional teaching approach.

Gee (2007) and Unlusoy et al. (2010) revealed that males are more likely to use digital game on learning than females. But the main findings of this study highlighted three parts for learning achievements: (1) female students who learned with the RES-battle game-based learning approach were found to have improved learning achievements on the topic better than those who learned with the traditional teaching approach; (2) male students who learned with the RES-battle game-based learning approach were found to have improved learning achievements on the topic better than those who learned with the traditional teaching approach; (3) each learning approach (i.e., the RES-battle game-based learning approach and the traditional teaching approach) benefited both female and male students' learning achievement to the same extent. In addition, there are three parts for awareness: (1) female students who learned with the RES-battle game-based learning approach were found to have better awareness on saving energy in residence than those who learned with the traditional teaching approach; (2) male students who learned with 
the two different learning approaches were found to have awareness on saving energy in residence to the same extent; (3) the RES-battle game-based learningapproach promoted awareness among both female and male students in a similar manner, while the traditional teaching approach promoted better awareness in male students than in female students. Possible reasons for this observed difference might include the ways of learning and exploring the knowledge, and sensing with daily life household appliances. While participating in the RES-battle game-based learning, the students were encouraged to explore elements in the game, discuss what they found with their peer, and construct their own knowledge. Moreover, they had the opportunity to interact with virtual scenario and graphical simulation within the REB-battle game. It resulted that awareness and learning achievement were supported among the female and male students. Whereas, awareness was promoted among male students better than female students while learning with the traditional teaching. These findings comply with the view expressed by Yang and Chen (2010) that the digital game with encouraging students explore and construct knowledge instead of memorize the answers could reduce the learning achievements' differences between males and females.

Consequently, we could suggest that to support learning and decrease the gap between females and males on learning achievements and awareness on energy consumption and conservation, the game-based inquiry learning approach could be used well than the traditional teaching approach. It means that the game can provide the opportunities for interaction on game screen and also with other students. It implies that we need to accommodate the encoding and decoding of graphics and elements through the game. Such that the game would promote students to inquire evidence for constructing the knowledge.

\section{References}

Abrahamse, W., Steg, L., Vlek, C., \& Rothengatter, T. (2005). A review of intervention studies aimed at household energy conservation. Journal of Environmental Psychology, 25(3), 273-291.

Agosto, D. E. (2004). Girls and gaming: a summary of the research with implications for practice. Teacher Librarian, 31(3), 8-14.

Boyde, S. (2002). Green lubricants. Environmental benefits and impacts of lubrication. Green Chemistry, 4(4), 293-307.

Cai, Y., Lu, B., Zheng, J., \& Li, L. (2006). Immersive protein gaming for bio edutainment. Simulation \& Gaming, 37(4), 466-475.

Chen, Z. H., Liao, C. C. Y., Chien, T. C., \& Chan, T. W. (2011). Animal companions: fostering children's effort-making by nurturing virtual pets. British Journal of Educational Technology, 42(1), 166-180.

Chen, Z. H., Lu, C. H., Chou, C. Y., Chen, L. C., Ching, C. W., \& Wan, C. F. (2013). My-investment: using digital games to help children learn financial management. Research \& Practice in Technology Enhanced Learning, 8(2), 277-290.

Chiu, M.-H., Chou, C.-C., \& Liu, C. J. (2002). Dynamic processes of conceptual change: Analysis of constructing mental models of chemical equilibrium. Journal of Research in Science Teaching, 39(8), 688-712.

Connolly, T. M., Stansfield, M., \& Hainey, T. (2007). An application of games-based learning within software engineering. British Journal of Educational Technology, 38(3), 416-428. 
DeWaters, J. E., \& Powers, S. E. (2011). Improving energy literacy among middle school youth with project-based learning pedagogies. In Proceedings of the 41st ASEE/IEEE Frontiers in Education Conference. Rapid City, South Dakota, USA.

Dorji, U., Panjaburee, P., \& Srisawasdi, N. (2014). Effects of gender differences and learning performance within residence energy saving game-based inquiry playing. In Proceedings of the 22nd International Conference on Computers in Education 2014. Asia-Pacific Society for Computers in Education, Japan.

Eck, R. V. (2006). Digital game-based learning: It's not just the digital natives who are restless. EDUCAUSE Review, 41(2), 16-30.

Evans, G. W., Brauchle, G., Haq, A., Stecker, R., Wong, K., \& Shapiro, E. (2007). Young children's environmental attitudes and behaviors. Environment and Behavior, 39(5), 635-658.

Gee, J. P. (2006). Are video games good for learning? Paper presented at the Curriculum Corporation 13th National Conference, Adelaide. Retrieved from http://cmslive.curriculum.edu.au/verve/_ resources/gee_paper.pdf.

Gee, J. P. (2007). In what video games have to teach us about learning and literacy. Basingstoke: Palgrave Macmillan.

Gustafson, K. L., \& Branch, R. M. (2002). Survey of instructional development models (4th ed.). Syracuse, NY: ERIC Clearinghouse on Information \& Technology.

Haakana, M., Sillanpää, L., \& Talsi, M. (1997). The effect of feedback and focused advice on household energy consumption. In Proceedings of the ECEEE 1997 Summer Study on Energy Efficiency. Retrieved from http://www.eceee.org/library/conference_proceedings/eceee_Summer_Studies/ 1997/Panel_4/p4_6/paper.

Kang, N. N., Cho, S. H., \& Kim, J. T. (2012). The energy-saving effects of apartment residents' awareness and behavior. Energy and Buildings, 46, 112-122.

Kiili, K. (2007). Foundation for problem-based gaming. British Journal of Educational Technology, 38(3), 394-404.

Lee, Y. C., \& Chen, P. M. (2009). A computer game as a context for non-routine mathematical problem solving: The effects of type of question prompt and level of prior knowledge. Computers \& Education, 52(3), 530-542.

Maharaj-Sharma, R. (2012). What are upper primary school students' perceptions of science? The Trinidad and Tobago context. Retrieved from http://uwispace.sta.uwi.edu/dspace/handle/2139/ 13705.

Moll, H. C., Noorman, K. J., Kok, R., Engström, R., Throne-Holst, H., \& Clark, C. (2005). Pursuing more sustainable consumption by analyzing household metabolism in European countries and cities. Journal of Industrial Ecology, 9(1-2), 259-275.

Moreno-Ger, P., Burgos, D., Martínez-Ortiz, I., Sierra, J. L., \& Fernández-Manjón, B. (2008). Educational game design for online education. Computers in Human Behavior, 24(6), 2530-2540.

Mueller, F., Gibbs, M. R., \& Vetere, F. (2010). Towards understanding how to design for social play in exertion games. Personal and Ubiquitous Computing, 14(5), 417-424.

Papastergiou, M. (2009). Digital game-based learning in high school computer science education: impact on educational effectiveness and student motivation. Computers \& Education, 52(1), 1-12.

Paraskeva, F., Mysirlaki, S., \& Papagianni, A. (2010). Multiplayer online games as educational tools: facing new challenges in learning. Computers \& Education, 54(2), 498-505.

Prensky, M. (2007). Digital game-based learning. St. Paul, MN: Paragon House.

Schwedes, H., \& Dudeck, W.-G. (1996). Teaching electricity by help of a water analogy. In G. Welford, J. Osborne, \& P. Scott (Eds.), Research in science education in Europe: Current issues and themes. London: Falmer Press.

Slotta, J. D., \& Chi, M. T. (2006). Helping students understand challenging topics in science through ontology training. Cognition and Instruction, 24(2), 261-289.

Sofoluwe, S. A. (2007). Information and communication technology and administrative effectiveness of Nigeria universities. International Journal of Educational Management, 2(3), 43-56.

Spraggins, C. C., \& Rowsey, R. E. (1986). The effect of simulation games and worksheets on learning of varying ability groups in a high school biology classroom. Journal of Research in Science Teaching, 23(3), 219-229.

Srisawasdi, N., \& Kroothkeaw, S. (2014). Supporting students' conceptual development of light refraction by simulation-based inquiry with dual-situated learning model. Journal of Computers in Education, 1(1), 49-79. 
Torres, M., \& Macedo, J. (2000). Learning sustainable development with a new simulation game. Simulation \& Gaming, 31(1), 119-126.

Unlusoy, A., de Haan, M., Leseman, P. M., \& van Kruistum, C. (2010). Gender differences in adolescents' out-of-school literacy practices: a multifaceted approach. Computers \& Education, 55(2), 742-751.

van de Berg, E., \& Grosheid, W. (1993). Electricity at home: Remediating alternative conceptions through redefining goals and concept sequences and using auxiliary concepts and analogies in 9th grade electricity education. In J. Novak (Ed.), Proceedings of the third international seminar on misconceptions and educational strategies in science and mathematics. Ithaca, NY: Cornell University. Retrieved from http://www.mlrg.org/proc3pdfs/vandenBerg_Electricity.pdf.

Vastamäki, R., Sinkkonen, I., \& Leinonen, C. (2005). A behavioral model of temperature controller usage and energy saving. Personal and Ubiquitous Computing, 9(4), 250-259.

Vogel, J. J., Vogel, D. S., Cannon-Bowers, J., Bowers, C. A., Muse, K., \& Wright, M. (2006). Computer gaming and interactive simulations for learning: a meta-analysis. Journal of Educational Computing Research, 34(3), 229-243.

Yang, J. C., \& Chen, S. Y. (2010). Effects of gender differences and spatial abilities within a digital pentominoes game. Computers \& Education, 55(3), 1220-1233.

Yang, J. C., Chien, K. H., \& Liu, T. C. (2012). A digital game-based learning system for energy education: an energy conservation pet. The Turkish Online Journal of Educational Technology, 11(2), 27-37.

Ugyen Dorji received his Master's degree in Science and Technology education at Institute for Innovative Learning, Mahidol University, Thailand. He is currently working as a teacher at Gelephu Higher Secondary School, Gelephu Thromde, Sarpang, Bhutan. He is interested in all aspects of Science and Technology education.

Patcharin Panjaburee received Ph.D. degree in Science and Technology Education from the Institute for Innovative Learning, Mahidol University in Thailand. She is currently working as an Assistant Professor of Computer Education at the Institute for Innovative Learning, Mahidol University, Thailand. She is interested in computer-assisted testing, expert systems, knowledge engineering, technology-enhanced learning, and computer science and mathematics education. She is the corresponding author of this paper.

Niwat Srisawasdi received Ph.D. degree in Science and Technology Education from the Institute for Innovative Learning, Mahidol University in Thailand. he is currently working as an Assistant Professor of Science Education at the Division of Science, Mathematics, and Technology Education, Faculty of Education, Khon Kaen University, Thailand. He is interested in technology-enhanced science education, and technological pedagogical and content knowledge for science teacher. 